\title{
Training of Primary School Specialists Taking Into Account Up-to-Date Opportunities for Self-Improvement
}

\author{
Yuliia Shevchenko \\ Bogdan Khmelnitsky Melitopol State Pedagogical University \\ Svitlana Dubiaha \\ Bogdan Khmelnitsky Melitopol State Pedagogical University \\ Volodymyr Huz \\ Bogdan Khmelnitsky Melitopol State Pedagogical University \\ Valentyna Melash \\ Bogdan Khmelnitsky Melitopol State Pedagogical University \\ Anastasiia Varenychenko \\ Bogdan Khmelnitsky Melitopol State Pedagogical University \\ Yuliia Saienko \\ Bogdan Khmelnitsky Melitopol State Pedagogical University
}

\begin{abstract}
The purpose of the research is to analyze the training of primary school specialists taking into account the up-to-date opportunities for self-improvement at the stage of university training and at the early stage of professional activity (the first 3-5 years after starting work at school). In order to obtain empirical data, a diversified diagnostic model has been developed, within which a questionnaire has been conducted and a method of presenting a portfolio of professional self-improvement has been applied. The research based on the tactics of self-reflection of graduates has showed a high level of formation of professional selfimprovement, which is partly due to the selection criteria of respondents. Comparison of the results with the data of the studied group of respondents - primary school teachers with teaching experience $\geq 5$ years allowed assessing the dynamics of professional self-improvement at the stages of pre-service and in-service training, as well as identifying promising areas of professional self-improvement, which should be emphasized during the university training of future primary school teachers.
\end{abstract}

Keywords: personal development, university training, elementary school teacher, professional training, self-reflection 


\section{INTRODUCTION}

In the context of scientific and technological progress, the issue of a standardized sustainable set of competences that a school teacher of any educational degree, including a primary school teacher, should possess, looks anachronistic. While the process of university professional training takes only an average of 4-5 years, then the process of further professional activity of a teacher sometimes covers an interval of 3040 years (Teaching and Learning..., 2018), during which 2-3 generations of pupils change. Qualitative performance of educational tasks by a primary school teacher is possible only under the condition of the teacher's flexibility and his ability to adapt both to new working conditions and to the performance of social tasks assigned by the state to the institute of school education (Turrado-Sevilla et al., 2020). The fundamental role in the proper professional functioning of the teacher is played by the attitude to the concept of self-improvement laid down in the process of professional self-determination and further professional training (Gough, 2016; Kadyrova, 2020).

The TALIS survey has also showed that more than $90 \%$ of teachers choose the teaching profession, motivating this with the opportunity to influence the development of children and youth. More than $80 \%$ of respondents have stated that the teaching profession is attractive to them because of the opportunity to contribute to the development of the society. The numbers are impressive, especially when compared to the pragmatic goals of the teaching profession: for example, the possibility of building a career has influenced the choice of profession only about $60 \%$ of respondents, teaching as a source of reliable income has motivated to become a teacher - about $65 \%$ of respondents (Teaching in Focus No. 29, 2019). The data outlined indicate the dominance of altruistic-idealistic motives in the choice of the teaching profession and pose an urgent requirement to provide adequate support to the teacher at all stages of his pre-service and in-service pedagogical activity for highly effective performance of the assigned tasks.

Conscious attitude to the concept of professional pedagogical self-improvement will contain the following stages:

- modern professional training of future teachers;

- continuous learning prospects of teachers' training (Sergeeva, 2016).

Obstacles to the professional self-improvement of primary school teachers are their low social professional activity, conservatism, indifference to innovation due to a number of objective and subjective factors that become an impediment to the reform of primary school. In this regard, there is a need to determine the theoretical and methodological foundations of professional self-development of future teachers, to identify pedagogical conditions for training a positive attitude to professional self-improvement in university training, which is the subject of this research.

The purpose of the research is to comprehensively analyze the training of primary school specialists taking into account up-to-date opportunities for self-improvement at the stage of university training and at the early stage of professional activity (the first 3-5 years after starting work at school). The implementation of the purpose outlined involves the implementation of a number of objectives, namely:

1) development of diagnostic methods for determining the formation of professional selfimprovement orientations for graduates of specialty 013 Primary education and determining the degree of implementation of professional self-improvement settings for primary school teachers with work experience $\geq 5$ years;

2) conducting questionnaires and analyzing the portfolio of professional self-improvement;

3) analysis and generalization of data in order to determine the nature of the representation of attitudes to professional self-improvement in respondents of both groups, comparing the results of the research;

4) revealing current directions of stimulating professional self-improvement of future primary school teachers in the process of university training. 


\section{LITERATURE REVIEW}

The concept of professional self-improvement of teachers is an important direction of modern investigations. Self-organized and self-managed professional self-development of a primary school teacher means (based on the insights of Hart (2020): a) creation by the teacher of his own plans of personal professional self-improvement with definition of the purposes for self-improvement and self-development; b) encouraging teachers to find resources, tools and services for professional self-development that foremost take into account individual features, as opposed to requiring the use of only corporate resources, tools and self-improvement services (for instance, standardized periodic advanced training courses); c) providing the teacher with some reserve protected learning time for the implementation of plans for professional self-improvement and self-development according to individual rates; d) encouraging teachers to document their own progress in professional development with the indication of evidence in the personal digital portfolio, as opposed to the centralized management of this process by the school administration and education authorities; e) providing teachers with the opportunity to share experiences and plans for professional self-improvement in the environment of pedagogical associations and communities.

Gough (2016) considers the features of organizing the university training of teachers who stand in the way of the introduction of sustainable development's principles and suggests ways to solve them. Sergeeva (2016) notes that the lack of clear requirements for the competences of primary school teachers has a negative impact on the content of university training. As a result, many teachers are passive in their pedagogical activities; they have no desire to introduce innovations in their work. Sergeeva (2017), considering the content of the concept of professional self-improvement of primary school teachers, pays attention to its structural components, a holistic and high-quality system of professional training, professional competences, professional orientation and professional flexibility. Kadyrova (2020), analyzing the professional and pedagogical competences of primary school teachers, notes the contradictions between the growing requirements of scientific and technological development to the professional training and functioning of primary school teachers. As a result, teachers are not ready for the self-development of the main part of the necessary professional competences required from a qualified pedagogical person in a dynamically renewed society. This encourages universities to actively participate in transformation processes, which are designed to teach future teachers the tactics of continuous self-improvement in order to adapt to new professional challenges.

Scientists note that the lack of initiative for self-improvement among primary school teachers, deviations in the ideological sense from modern pedagogical strategies, improvement of the ability to teach affects the implementation of the didactic paradigm "curriculum thought and politics" and negatively affects the results of educational achievements of primary school pupils (Hao et al., 2020; Olkhova, 2021). Flood and Brown (2018) positively evaluate the use of Theories of Action (TofA) tools in order to improve the professional activity of teachers of different levels of schools through the example of implementing a strategy of partnership between an academic and three schools. Liu et al. (2019) explores the internal motivational prerequisites for professional self-improvement of teachers. Motivation is interpreted as a reflection of the state and levels of professional development of teachers. Intrinsic motivation is an ideal way to intensify the high level of professional development of teachers. It has been revealed in a specific study that the external motivation of teachers can be transformed into a stable model of intrinsic motivation. The current level and value orientations of professional development of teachers, the level of development of pedagogical practice, psychological background of teachers in development processes and interaction between these three aspects of professional self-development influence the dynamics of intrinsic motivation as a prerequisite and consequence of professional pedagogical self-improvement.

Chen et al. (2020) considers the issue of information literacy of primary school teachers in the paradigm of modernization of the teaching staff. Lack of information literacy skills of modern primary school teachers has been revealed, as well as significant differences in information literacy, which are determined by additional factors, namely: gender, age, educational background, area, school type. Özdemir et al. (2020) investigates the consequences of the influence of the school administration's management model of educational institutions on the representation of teachers, in particular of primary school, about their 
perception of the effectiveness of their pedagogical activities. It has been found that there is a direct connection between these factors: the models of instructional leadership behaviors applied by school leaders contribute to the positive motivation and focus of teaching staff on professional self-development. Yusof et al. (2017) aims to determine the level of leadership among primary school teachers (based on a largescale study involving 250 teacher-respondents) and to identify factors that affect the leadership qualities of primary school teachers. It is proposed to introduce courses for stimulating competences and leadership qualities for primary school teachers in order to promote professional self-development and to improve leadership skills.

Pang (2020) investigates the application of Assessment for Learning (AfL) strategies in teaching by primary school teachers. The results of the study have showed that reflexive practices in pedagogical strategies make it possible to increase the effectiveness of teaching at primary school to a professional level, to stimulate professional self-growth and self-improvement and also to increase the results of pupils' academic achievements. Herewith, Bentri (2017) examines the readiness of primary school teachers to introduce new curriculum requirements, which requires teachers to be able to adapt to new pedagogical requirements. The obtained results have revealed the directions of primary school teachers' activities that in the future need professional self-improvement on the part of primary school teachers, namely in terms of classroom management, encouraging pupils in the learning process, readiness to change learning strategies. The requirement is set up for the intensive and sustainable qualities of modern vocational training for primary school teachers to acquire the necessary professional competences.

Yue (2019) analyzes the process of formation of professional qualities of future teachers in the framework of university training. The following important factors of professional formation, namely: reflexive, communicative skills, education wisdom, moral concepts of pedagogical activity, ability to selfdevelopment are singled out. Particular attention is paid to the professionalization and advanced training of primary and secondary school teachers. It has been noted that currently the training of teachers mainly focuses on theoretical knowledge and lack of practical experience in teaching activities. Luo and Xu (2019) define rationalized self-consciousness, self-reflection, self-organization, adaptability and autonomy as primary factors of professional self-development. The viewpoint at the professional self-improvement of primary school teachers as on a process of self-renewing deserves to be highlighted. Self-reflection is also recognized as a key prerequisite for professional self-improvement of teachers in the scientific investigation of Setyaningrahayu et al. (2019). The works of Tatto (2021), Peralta and Tatto (2018) focus on the selfimprovement of primary school teachers towards improving methods of teaching mathematics, highlighting the role of the research component in the approach to teaching.

Demir-Basaran and Sesli (2019) study the trends of involvement of primary school teachers in the concepts of lifelong learning based on the analysis of a set of relevant factors (gender, professional sphere, level of education, professional experience and frequency of reading scientific and popular science literature). Analysis of the literature on the topic has made it possible to identify the current directions of the problem development of primary school specialists' self-improvement at the stages of university education and direct practical labor activity. However, there is an obvious lack of data on the identification of factors influencing the professional self-improvement of applicants for the profession of a primary school teacher, as well as of teachers - practitioners who have recently started their professional activities at primary school.

\section{MATERIALS AND METHODS}

The results of the TALIS-2018 monitoring study have been taken into account when developing the methodology for diagnosing readiness and the actual level of implementation of modern models of professional self-improvement of primary school teachers (Teaching and Learning..., 2018). The criteria identified in the research have been used to assess primary school teachers through a number of common functional factors and preconditions determined by the pedagogical professional environment. In general, in the process of preparing the present scientific investigation, the following methods have been used, namely: analysis of scientific literature, comprehensive analysis of the concept of professional self- 
improvement, method of observation and description, questionnaire, portfolio method, functional method, method of comparison, method of mathematical and statistical data processing, generalization of the research results, etc.

In order to conduct the diagnostic and practical part of the research, 2 groups of respondents have been involved, each of which contained 20 people. The first group consisted of 20 graduates of the specialty 013 Primary education (last semester of study, the criterion for selecting students was the academic success of mastering disciplines not lower than level C), participation in scientific activities of the university (indicate the university); the second group consisted of 20 primary school teachers with teaching experience $\geq 5$ years (but not less than 3 full years), with an average score of the diploma supplement not lower than level $\mathrm{C}$ (according to the criteria of the Bologna system). The research was conducted through a questionnaire, the purpose of which is to identify the predicted (desired) and actual levels of the potential's implementation of professional self-improvement within the framework of pedagogical activity. The survey was conducted anonymously and decentrally. Respondents could fill in the questionnaire in accordance with the questions within 3 days allotted for this purpose in any (written / printed) form. Also, in order to assess the formation and dynamics of self-improvement orientations, the method of presentation of students' and teachers' portfolios was used, where respondents presented their self-improvement activities in the document Word and Power Point (optional) of no particular format.

In general, the research has covered several stages, namely: 1) development of the author's model of the diagnostic questionnaire based on the analysis of scientific sources on the topic; 2) conducting questionnaires, evaluation, analysis and generalization of data; 3) analysis of the presented portfolios of professional self-improvement, evaluation and generalization of indicators; 4) identification of ways of active and sustainable stimulation of students - future teachers of primary school to use up-to-date opportunities for self-improvement. The assessment structure of two groups of respondents is presented in Table 1.

TABLE 1 SCHEME FOR ASSESSING TH FORMATION AND IMPLEMENTATION OF
PROFESSIONAL SELF-IMPROVEMENT OF DEGREE-SEEKING
STUDENTS AND REPRESENTATIVES OF THE PROFESSION OF
PRIMARY SCHOOL TEACHER

\begin{tabular}{|l|c|c|}
\hline & Questionnaire & Portfolio \\
\hline Group of students & 100 points & 100 points \\
\hline Group of students & 100 points & 100 points \\
\hline & 200 points & 200 points \\
\hline
\end{tabular}

When assessing the formation of graduate students' self-improvement settings, as well as assessing the manifestations of young teachers' self-improvement, the lack of formalized performance evaluation techniques has been revealed. This is due to the very nature of the concept of professional self-improvement, which is very abstract and the indicators of which are quite relative and personality-determined. For maximum objectivity and completeness of the data, author's questionnaires have been proposed, taking into account a variety of factors that may affect the formation and direct implementation of selfimprovement. In general, the questionnaires (Appendix A; Appendix B) are designed to stimulate selfreflection and an abstract view of one's own professional activity. The answer to each question was rated on a scale of 0-5 points. The result was evaluated at 0 points if the question was ignored. Furthermore, not a positive response indicator was taken into account (for instance, a high assessment of professional competences' formation level of a primary school teacher on a scale of 1-10 points), but the depth and completeness of the analytical, self-reflective component of the responses. The basis for assessing the questionnaire survey of a group of students is the thesis that a deep awareness of the features of their readiness for future professional activity, a clear understanding of the strengths and weaknesses of their own pedagogical personality, conscious and self-critical attitude to professional training and directly to the 
results of work, manifestation of activity in order to overcome the shortcomings of professional training (both at the pre-service stage and at the in-service stage) form the basis and catalyst of professional selfimprovement. When assessing the portfolio, special attention was paid to the activity component.

When assessing the questionnaire survey of a group of teachers (especially questions 1-2, 8-11), the emphasis was placed on the effectiveness of professional self-improvement measures and the current activity component for professional self-improvement. The completeness of the representation of one's own experience of professional self-improvement and the availability of evidence of the declared results were taken into account in the portfolio (for instance, availability of scientific or methodological works, keeping a diary on self-improvement, feedback from pupils'/ parents' teams, school administration, involvement in teachers' online and offline communities, certificates of training, advanced training courses, etc.).

The following levels of verbal assessment of professional self-improvement have been identified, namely:

- unsatisfactory: 0-99 points;

- satisfactory: 100-139 points;

- sufficient: 140-179 points;

- high: 180-200 points.

\section{RESULTS}

The results of the formation of self-improvement settings of the students' group of the last year of study on the specialty 013 Primary education are presented in Table 2.

TABLE 2

THE RESULTS OF THE DIAGNOSTIC OF A FROUP OF STUDENTS

\begin{tabular}{|c|c|c|c|c|}
\hline No & Questionnaire & Portfolio & Total & $\begin{array}{l}\text { Level of formation (verbalized } \\
\text { indicator) }\end{array}$ \\
\hline 1 & 80 & 86 & 166 & Sufficient \\
\hline 2 & 87 & 89 & 176 & Sufficient \\
\hline 3 & 75 & 81 & 156 & Sufficient \\
\hline 4 & 92 & 94 & 186 & High \\
\hline 5 & 79 & 86 & 165 & Sufficient \\
\hline 6 & 91 & 95 & 186 & High \\
\hline 7 & 89 & 93 & 182 & High \\
\hline 8 & 95 & 96 & 191 & High \\
\hline 9 & 88 & 89 & 177 & Sufficient \\
\hline 10 & 78 & 80 & 158 & Sufficient \\
\hline 11 & 86 & 85 & 171 & Sufficient \\
\hline 12 & 90 & 92 & 182 & High \\
\hline 13 & 67 & 78 & 145 & Sufficient \\
\hline 14 & 90 & 90 & 180 & High \\
\hline 15 & 85 & 94 & 179 & Sufficient \\
\hline 16 & 89 & 91 & 180 & High \\
\hline 17 & 83 & 88 & 171 & Sufficient \\
\hline 18 & 88 & 90 & 178 & Sufficient \\
\hline 19 & 77 & 79 & 156 & Sufficient \\
\hline 20 & 85 & 89 & 174 & Sufficient \\
\hline Av.* & 84.7 & 83.8 & $\sim 168.5$ & Sufficient \\
\hline
\end{tabular}

Note: *Av.-Averagely. 
Thus, the high level of formation of settings to professional self-improvement was demonstrated by 7 respondents $(35 \%)$, sufficient -13 respondents $(65 \%)$. According to the method of selection of respondents, no results with satisfactory level and unsatisfactory levels are expected. The average result of formation of settings to professional self-improvement within the group was 168.5 points, which in percentage terms is $84 \%$. However, the result of the respondent 13 amounted only 145 points, which is only 5 points above the critical limit of satisfactory level. In general, the indicators obtained are quite high; this indicates the effectiveness of the consistent work of university teachers and other components of university training in the formation of students' orientation towards a conscious attitude to the profession of a primary school teacher, self-reflection, and an orientation towards high pedagogical standards. This is evidenced by questions 15-16, 24 (a significant number of respondents pointed to the personal example of university teachers as a reference point for professional self-growth), 25.

However, an important prerequisite for a sufficient and high level of self-improvement is the high academic performance of respondents: analysis of the transcript of the questionnaires showed that 5 out of 7 respondents, who demonstrated a high level, have a level of academic success A, B (in the range of 8597 points) according to the Bologna evaluation system. At the same time, the respondent with the lowest indicator (No.13, 145 points scored) has $78 \%$ of the results of mastering university subjects - at the level of $\mathrm{C}$. The answers to questions 17-23 provide insights to understand the professional orientation of the respondent and make it possible to assess the risks of abandoning a teacher's career. In the framework of our research, this risk can be estimated at $15 \%$, which is a considerable indicator. This can be avoided by consistent preparing of students for numerous difficulties faced by young professionals in the field of primary education in the early stages of professional activity.

Regarding the issue of the financial side of professional self-improvement, $62 \%$ of respondents are willing to spend moderate money if they can improve the results of their pedagogical activity. About 5\% of respondents answered that it can be regarded as a categorical inadmissibility of any financial costs, which is motivated by extremely low salary of primary school teachers. The predicted favorable factors for professional self-growth (questions 13,18) in the framework of future professional activities, mentioned by students, include a wage, sufficient to meet the actual vital needs of a young person, and psychological pleasure from communicating with the collective of primary school students and the teaching staff (colleagues). Negative factors (questions 14, 19-20) are as follows: lack of funds, discomfort in the teaching staff and excessive parental interference in the activities of primary school teachers (hostile, biased attitude towards young professionals, total control over the activities of teachers, restrictions on freedom of pedagogical action by trying to strictly monitor actions of the teacher).

By the way, the results of the survey revealed a direct interrelationship between personal attitude to self-improvement and its professional expression (questions 1-3). Along with this, the more critical the respondent is to his own level of professional development, the more meticulous is his attitude to the level of formation of professional competences of groupmates. $68 \%$ of the analysis's results of questions 4-7 and 15 of the questionnaire also showed a higher level of self-assessment of their own professional development' traits and readiness to perform professional duties compared to a similar assessment of professional development's traits of their peers. $16 \%$ of respondents very vaguely determine the prospects for professional self-improvement (questions 8, 10, 13, 14, 21-23); 12\% of respondents do not show visible, conscious activity for professional growth (question 9). The data of processing answers to questions 11-12 have revealed that students are more aware of information about free ways of professional selfimprovement (in most cases they are connected with the use of free online resources) and much less know about paid ones (participation in paid conferences, trainings, courses on advanced training, etc.). the purchase of special literature was most often mentioned as one the paid methods. The answers to questions 8, partly questions 21-23 allow summarizing the information and identifying directions of activity of primary school teachers, from which the respondents, interviewed by us, often need help on the way to professional self-growth (Table 3). 
TABLE 3

ACTUAL DIRECTIONS OF PROFESSIONAL SELF-IMPROVEMENT OF FUTURE PRIMARY SCHOOL TEACHERS IN THE FRAMEWORK OF UNIVERSITY TRAINING (IN DESCENDING ORDER OF DEMAND)

\begin{tabular}{|c|l|c|}
\hline $\begin{array}{c}\text { No. of } \\
\text { suggestion }\end{array}$ & \multicolumn{1}{|c|}{ Direction } & $\begin{array}{c}\text { Percentage of } \\
\text { respondents } \\
\text { who consider it } \\
\text { relevant }\end{array}$ \\
\hline 1. & $\begin{array}{l}\text { Complex of pedagogical activity with children of primary school age } \\
\text { within the framework of inclusive education. Overcoming psychological } \\
\text { barriers concerning teaching in an inclusive classroom. }\end{array}$ & $65 \%$ \\
\hline 2. & $\begin{array}{l}\text { Mastering ICT for work in a multimedia classroom and in case of } \\
\text { distance education mode. }\end{array}$ & $42 \%$ \\
\hline 3. & $\begin{array}{l}\text { Deeper knowledge of the features of age psychology of primary school } \\
\text { pupils. }\end{array}$ & $37 \%$ \\
\hline 4. & $\begin{array}{l}\text { Knowledge of personal time management and organizational skills } \\
\text { required in the context of pedagogical activities in primary school. }\end{array}$ & $36 \%$ \\
\hline 5. & $\begin{array}{l}\text { Extention of knowledge and skills of accountability and control } \\
\text { mechanisms within the pedagogical activities of the primary school } \\
\text { teacher. }\end{array}$ \\
\hline 6. & $\begin{array}{l}\text { Cognition of directions and practical ways of professional self- } \\
\text { improvement. }\end{array}$ & $29 \%$ \\
\hline 7. & \begin{tabular}{l} 
Improving skills of interaction with parents' teams. \\
\hline
\end{tabular}
\end{tabular}

The identified directions are important in the university training of future primary school teachers, especially in order to overcome the uncertainty of degree-seeking students in these aspects of professional activity and to stimulate opportunities for self-improvement of students for the profession of primary school teacher in the paradigm of university education. The results of diagnosing the degree of implementation of the professional self-improvement settings of primary school teachers with work experience of $\geq 5$ years are presented in Table 4.

TABLE 4

THE RESULTS OF THE DIAGNOSTIC OF A GROUP OF TEACHERS

\begin{tabular}{|l|c|c|c|c|}
\hline No & Questionnaire & Portfolio & Total & $\begin{array}{c}\text { Level of formation (verbalized } \\
\text { indicator) }\end{array}$ \\
\hline 1 & 75 & 81 & 156 & Sufficient \\
\hline 2 & 88 & 85 & 173 & Sufficient \\
\hline 3 & 95 & 91 & 186 & High \\
\hline 4 & 72 & 74 & 146 & Sufficient \\
\hline 5 & 77 & 80 & 157 & Sufficient \\
\hline 6 & 71 & 85 & 156 & Sufficient \\
\hline 7 & 88 & 73 & 161 & Satisfactory \\
\hline 8 & 65 & 66 & 131 & Sufficient \\
\hline 9 & 82 & 83 & 165 & Sufficient \\
\hline 10 & 88 & 79 & 167 & Sufficient \\
\hline 11 & 87 & 89 & 176 & High \\
\hline 12 & 88 & 92 & 180 & Satisfactory \\
\hline 13 & 63 & 71 & 134 & \\
\hline
\end{tabular}




\begin{tabular}{|l|c|c|c|c|}
\hline 14 & 80 & 73 & 153 & Sufficient \\
\hline 15 & 73 & 74 & 147 & Sufficient \\
\hline 16 & 94 & 93 & 187 & High \\
\hline 17 & 65 & 78 & 143 & Sufficient \\
\hline 18 & 78 & 80 & 158 & Sufficient \\
\hline 19 & 87 & 92 & 179 & Sufficient \\
\hline 20 & 96 & 97 & 193 & High \\
\hline Av.* & 80.6 & 81.8 & $\sim 162.4$ & Sufficient \\
\hline
\end{tabular}

Note: ${ }^{*}$ Av. - Averagely

The results of teachers' diagnostics have showed lower indicators. However, this may be due to a more substantive approach to evaluating their performance. In general, the average level for this group of respondents remained within the sufficient level $(\sim 162.4$ points, which in the percentage representation is equivalent to $81 \%$ ). However, the distribution of points by individual indicators has significantly decreased. Thus, only 4 respondents (20\%) have showed a high level of implementation of professional selfimprovement settings, 14 respondents $(70 \%)$ - a sufficient level; there were also 2 respondents $(10 \%)$ with a satisfactory level in this group.

The analysis of the results, which have the greatest weight in the thematic field of the research, proves that as a result of answers to the question 19 , where it has been proposed to evaluate university preparation in the direction of the formation of a self-improvement orientation, the average statistical indicator has been only 6 points out of 10 possible. About $78 \%$ of respondents have faced difficulties during the first years of teaching (question 18); they have been forced to develop and implement (formally or informally) an individualized program of professional self-improvement in order to intensify the gaps in university training. Answers to question 17, which concerned the benefits of university training for professional activities, contained mostly indications of theoretical knowledge about the activities of primary school teachers and pointed to the lack of practical skills of professional activities in approximately the same areas that have been found in the analysis of the questionnaire of the students' group and are specified in Table 3.

More than half of the respondents in this group, when answering the questionnaire, noted that there was a reassessment of the actual level of assessment of the readiness to carry out the duties of a primary school teacher. Professional difficulties were also connected with the lack of attitudes and mechanisms of selfimprovement at the stage of university preparation for teaching at primary school. When answering question 9 , up to 88 teachers interviewed have stated that financial expenses caused by the intensity of professional self-improvement during the first 3-5 years of teaching activity are significant for their level of income. At the same time, the financial factor and lack of free time have become the most frequent $(56 \%$ and $64 \%$ respectively) answers to question 14 concerning the factors that negatively affect the process of professional self-improvement. Along with this, $95 \%$ of respondents gave a positive answer to question 13 (about wages as a tool to stimulate professional self-improvement). This may be applied when establishing a policy on payroll as well as it may be regulated at the legislative level. However, this practice exists; it has been already giving positive results in private schools.

Primary school teachers give significantly clearer answers to questions concerning the definition of directions of professional self-improvement (questions 7,22) and professional image in its desired and undesirable version in 5 years (questions 23-24). 11\% of the respondents admit the option of leaving the career of a primary school teacher, and $27 \%$ assume that the level of their professional self-improvement would significantly increase if they changed their institution of work to another (question 15, partly question 6). It is noticeable that when answering question 22 concerning the difficulties of professional development, which teachers have not yet been able to overcome in the first 5 years of their professional activity, the problem area has narrowed significantly compared to Table 3 , which summarizes the results of students by the outlined vector (Table 5). 
TABLE 5

\section{CURRENT DIRECTIONS OF PROFESSIONAL SELF-IMPROVEMENT OF PRIMARY SCHOOL TEACHERS IN THE EARLY STAGES OF PROFESSIONAL DEVELOPMENT (IN DESCENDING ORDER OF DEMAND)}

\begin{tabular}{|c|l|c|}
\hline $\begin{array}{c}\text { No. of } \\
\text { suggestion }\end{array}$ & \multicolumn{1}{|c|}{ Direction } & $\begin{array}{c}\text { Percentage of } \\
\text { respondents who } \\
\text { consider it relevant }\end{array}$ \\
\hline 1. & $\begin{array}{l}\text { Complex of pedagogical activity with children of primary school } \\
\text { age within the framework of inclusive education. Overcoming } \\
\text { psychological barriers concerning teaching in an inclusive } \\
\text { classroom. }\end{array}$ & $48 \%$ \\
\hline 2. & $\begin{array}{l}\text { Mastering ICT for work in a multimedia classroom and in case of } \\
\text { distance education mode. }\end{array}$ & $34 \%$ \\
\hline 3. & $\begin{array}{l}\text { Knowledge of personal and professional time management. } \\
\text { Cognition of foreign experience in the activities of primary school } \\
\text { teachers. }\end{array}$ & $34 \%$ \\
\hline
\end{tabular}

For number 1, in comparison with the data of students' survey, the demand decreased by $17 \%$; for number 2, only the difficulties of mastering digital technologies of organizing the educational process in primary school remained and the indicator of demand decreased by $8 \%$; direction 3 from Table 3 was almost completely exhausted. Knowledge of personal and professional time management remains relevant $(34 \%-$ unchanged compared to Table 3). Paragraphs 5-7 of Table 3 were removed. On the other hand, direction 4 was updated in $17 \%$ of respondents; it concerns the issue that respondents are motivated by the need to borrow effective foreign pedagogical practices, which is especially important for the formation of a globalized pedagogical environment.

\section{DISCUSSION}

Professional self-improvement of primary school teachers is a fundamental requirement of the modern educational system, determined by the intensity of evolutionary changes in human development and provided by the world development programs. Lifelong learning programs, development of plans on Sustainable Development in Teacher Education (McKeown and Hopkins, 2014) for the next decade, including Goal 4 in SDGs, which is formulated as ensuring inclusive and equitable quality education and promoting lifelong learning opportunities for all (Transforming our world..., 2015) declare, on the one hand, the efforts of university programs to cover the professional integrity of teachers as much as possible, and on the other hand - the objective impossibility of achieving this due to the extreme need of a modern teacher to make the process of professional self-improvement an integral part of his professional "I". The basic principles of professional self-improvement in accordance with the results obtained in the preparation of this scientific investigation should be relevance, individualized determinism, consistency and systematicity (Gough, 2016; Filho and Pace, 2016; Hopkins and Kohl, 2019). Prerequisite for professional self-improvement is the ability of self-reflection (Setyaningrahayu et al., 2019; Pang, 2020) and conscious and self-critical attitude to one's own professional competences and practice of their implementation in the paradigm of professional activity, which has formed the basis of diagnostic methods developed in the research.

The research has revealed a reassessment by students of pedagogical specialties of their own readiness for quality professional activity compared to teachers - practitioners. This is due to the lack of understanding by degree-seeking students of the features of routine practical teaching work in all the variety of daily tasks. This, in turn, is due to the prevalence of theoretical training of teachers, partly their isolation 
from reality, the lack of opportunities for practical pedagogical activities of students while studying at the university. Training and field attachment practices are often declarative, which is a consequence of both teachers' caution to fully trust the work of the junior school class to trainee students, and the reluctance of the trainee students to take responsibility by themselves for the preparation of the junior school classes, entrusted to them. This situation can be overcome through reporting tools based on the results of the internship, which would be based not on the formal representation of reporting documents on the practice, but the predominance of elements of self-reflection. The number of hours allocated to field attachment practice in university training also seems too small (Demir-Basaran and Sesli, 2019; Luo and Xu, 2019; Liu et al., 2019). In this case, it will be useful to adapt the experience of the national education system of the United Kingdom (Murray and Passy, 2014).

The above-mentioned monitoring study TALIS-2018 (Teaching and Learning..., 2018) has identified the following relevant directions in which lower secondary teachers feel the need for professional development, namely: approaches to individualized learning; teaching cross-curricular skills; teaching in a multicultural setting; students' behavior and classroom management; analysis and use of students' assessment; communicating with people from different cultures or countries; school management and administration; teacher-parent/guardian cooperation; knowledge of the curriculum; pedagogical competences in teaching; knowledge and understanding of subjects. In the diagnostic model, proposed by us, (at the questionnaire stage, question 8 in the students' questionnaire and question 7 in the teachers' questionnaire), the goal was also to identify the actual vectors of professional self-improvement, but already among teachers and future primary school teachers (in accordance with the subject of the research). Comparison of the results of these two studies leads to the conclusion that the areas of an individualized approach to teaching schoolchildren, training technologies and, in general, conducting professional communication in a multicultural environment, assessing educational achievements, knowledge of program subjects, etc. are less relevant for primary school teachers and degree-seeking students for this profession (Juskaite et al., 2019). Some de-actualized factors are due to differences between the educational process in primary and secondary schools, and some are determined by the features of the teacher in a relatively closed, non-internationalized pedagogical space of Ukraine. However, this is a direction, where the problem is not something that does exist; it is just still in the shadows, because there are currently few opportunities for multicultural professional dialogue. We assume that with the intensification of integration processes, this issue may soon become relevant and require a solution within the framework of professional selfimprovement programs for primary school teachers.

The method of questionnaire and analysis of the portfolio of professional self-improvement has showed that in the process of the first 5 years of work of a primary school teacher there is an intensive professional self-improvement, which requires significant moral and sometimes material costs. However, this makes it possible to eliminate about $50 \%$ of the directions of professional self-improvement that are relevant at the stage of university training (connected with the lack of academic training at higher educational institute (HEI)) and to more clearly outline the image of the ideal professional "I" for the next period of professional activity.

\section{CONCLUSIONS}

Current trends in human community development, scientific and technological progress, adaptive and innovative changes in the education system, the concept of lifelong learning and sustainable development goals acutely actualize the requirements for professional self-improvement of primary school teachers as a basic part of the educational system. In the course of the research, vectors of the general problem have been identified, which are currently poorly developed and require additional attention, namely: the lack of diagnostic tools to identify the formation of professional self-improvement settings within the framework of vocational training (at the university), the uncertainty of interrelationship between the attitudes of professional self-improvement initially formed at the university and their actual manifestation in the process of pedagogical activity in primary school. Developed diagnostic methods for determining the formation of professional self-improvement settings for graduates of specialty 013 Primary education and determining 
the degree of implementation of professional self-improvement orientations for primary school teachers with work experience $\geq 5$ years have demonstrated their effectiveness. The proposed methods can be used in practice in order to diagnose degree-seeking students for the profession of primary school teacher and teachers - practitioners or to identify features of professional self-improvement of teachers of other educational degrees or vocational schools and HEI.

Actual directions of stimulating the professional self-improvement of future primary school teachers are as follows: a complex of professional training for pedagogical activities with children of primary school age in the framework of inclusive education; mastering ICT for work in a multimedia class and in the conditions of distance education mode; in-depth knowledge of the features of the age psychology of primary school students; knowledge of personal time management and organizational skills required in the context of pedagogical interaction with primary school children; developing knowledge and improving skills in the mechanisms of accountability and control in the pedagogical activities of primary school teachers; increase of knowledge about potential directions and practical ways of professional self-improvement; improving skills of interaction with parents' teams. Further investigations may relate to the study of theoretical and practical features of professional self-improvement of teachers with more than 5 years of experience and gender mainstreaming in professional self-improvement. The implementation and analysis of the results of improving the practices of university training, aimed at stimulating professional self-improvement of future primary school teachers is also a relevant issue.

\section{REFERENCES}

Bentri, A. (2017). Mastery of primary school teacher pedagogy competency in curriculum 2013 implementation in Indonesia. The International Journal of Counseling and Education, 2(2), 78 84. https://doi.org/10.23916/0020170210020

Chen, M., Zhou, C., \& Wu, Y. (2020). Research on the model and development status of information literacy self-improvement ability of primary and secondary school teachers. In 2020 Ninth International Conference of Educational Innovation through Technology (EITT) (pp. 87-91). Piscataway: Institute of Electrical and Electronics Engineers. https://doi.org/10.1109/EITT50754.2020.00021

Demir-Basaran, S., \& Sesli, C. (2019). Examination of primary school and middle school teachers' lifelong learning tendencies based on various variables. European Journal of Educational Research, 8(3), 729-741. https://doi.org/10.12973/eu-jer.8.3.729

Filho, W., \& Pace, P. (2016). Teaching education for sustainable development at university level. Cham: Springer. https://doi.org/10.1007/978-3-319-32928-4

Flood, J., \& Brown, C. (2018). Does a theory of action approach help teachers engage in evidenceinformed self-improvement? Research for All, 2(2), 347-358. https://doi.org/10.18546/RFA.02.2.12

Gough, A. (2016). Teacher education for sustainable development: Past, present and future. In W. Filho \& P. Pace (Eds.), Teaching education for sustainable development at university level (pp.109122). Cham: Springer. https://doi.org/10.1007/978-3-319-32928-4_8

Hao, T., Luo, W., Deng, X., \& Wang, G. (2020). The status quo and countermeasures of the construction of primary school teachers under the concept of "curriculum thinking". Advances in Education, 10(4), 443-446. https://doi.org/10.12677/ae.2020.104074

Hart, J. (2020). Modern workplace learning 2020: How to build a continuous learning culture. London: Centre for Learning \& Performance Technologies.

Hopkins, C.A., \& Kohl, K. (2019). Teacher education around the world: ESD at the heart of education responsibilities and opportunities towards a sustainable future for all. In D. Karrow \& M. DiGiuseppe (Eds.), Environmental and sustainability education in teacher education. International explorations in outdoor and environmental education. Cham: Springer. https://doi.org/10.1007/978-3-030-25016-4_2 
Juskaite, L., Ipatovs, A., \& Kapenieks, A. (2019). Mobile technologies in physics education in latvian secondary schools. Periodicals of Engineering and Natural Sciences, 7(1), 187-196.

Kadyrova, F.D. (2020). Professional-pedagogical competence of the future primary school teacher. European Journal of Research and Reflection in Educational Sciences, 8(6), 79-82.

Liu, W.S., Li, X.W., \& Zou, Y.M. (2019). The formation of teachers' intrinsic motivation in professional development. Integrative Psychological and Behavioral Science, 53(3), 418-430. https://doi.org/10.1007/s12124-018-9465-3

Luo, Y., \& Xu, W. (2019). A review on the professional development of elementary education teachers in China. International Journal of Education and Learning, 1(2), 98-107. https://doi.org/10.31763/ijele.v1i2.48

McKeown, R., \& Hopkins, C. (2014). Teacher education and education for sustainable development: Ending the DESD and beginning the GAP. Toronto: York University.

Murray, J., \& Passy, R. (2014). Primary teacher education in England: 40 years on. Journal of Education for Teaching: International Research and Pedagogy, 40(5), 492-506. https://doi.org/10.1080/02607476.2014.956542

NCES. (2018). Teaching and Learning International Survey (TALIS), 2018. Retrieved from https://nces.ed.gov/surveys/talis/talis2018/

OECD. (2019). Teaching in Focus No. 29. https://doi.org/10.1787/fe6c9c0c-en

Olkhova, N.V. (2021). Development of the ideological culture of the future primary school teacher in the conditions of the new Ukrainian school. Scientific Bulletin of Mukachevo State University. Series "Pedagogy and Psychology", 7(3), 102-109.

Özdemir, G., Sahin, S., \& Öztürk, N. (2020). Teachers’ self-efficacy perceptions in terms of school principal's instructional leadership behaviours. International Journal of Progressive Education, 16(1), 25-40.

Pang, N.S.K. (2020). Teachers' reflective practices in implementing assessment for learning skills in classroom teaching. ECNU Review of Education. https://doi.org/10.1177/2096531120936290

Peralta, Y., \& Tatto, M.T. (2018). Preparing high-quality mathematics primary teachers: Exploring program strategies and standards in the United States, Russia, Poland, and Chinese Taipei. In M.T. Tatto., M. Rodriguez., W. Smith., M. Reckase., \& K. Bankov (Eds.), Exploring the mathematics education of teachers using TEDS-M data (pp. 31-67). Dordrecht: Springer. https://doi.org/10.1007/978-3-319-92144-0_3

Sergeeva, B.V. (2016). Professional self-improvement as a factor of modern teacher primary education to innovation activities. International Journal of Applied and Fundamental Research, 3. Retrieved from www.science-sd.com/465-24999

Sergeeva, B.V. (2017). The content of the concept "professional self-improvement of the teacher of primary education". Modern European Researches, 1, 102-109.

Setyaningrahayu, I., Widhi, P.R., \& Murtisari, E.T. (2019). The use of video-based reflection to facilitate pre-service English teachers' self-reflection. Indonesian JELT, 14(2), 147-165.

Tatto, M.T. (2021). Developing teachers' research capacity: The essential role of teacher education. Teaching Education, 32(1), 1-20. https://doi.org/10.1080/10476210.2020.1860000

Turrado-Sevilla, M.A., Mayo, I.C., \& Lucía, A. (2020). Characterising innovative primary schools and their teachers in Spain. International Journal of Learning and Change, 12(3), 248-264.

United Nations. (2015). Transforming our world: The 2030 agenda for sustainable development. Retrieved from https://www.un.org/ga/search/view_doc.asp?symbol=A/RES/70/1\&Lang=E

Yue, L. (2019). Construction of teachers' self-development platform from the perspective of higher education specialization. In 2019 5th International Workshop on Education, Development and Social Sciences (IWEDSS 2019) (pp. 821-823). London: Francis Academic Press. https://doi.org/10.25236/iwedss.2019.180

Yusof, H., Vyapuri, L., Jalil, N.A., Mansor, M., \& Noor, M.A.M. (2017). The factors affecting teacher leadership in Malaysian primary schools. International Journal of Academic Research in Business and Social Sciences, 7(6), 620-631. https://doi.org/10.6007/IJARBSS/v7-i6/3025 


\section{APPENDIX A: QUESTIONNAIRE FOR GRADUATES OF SPECIALTY 013 PRIMARY EDUCATION IN ORDER TO DETERMINE THE FORMATION OF PROFESSIONAL SELF-IMPROVEMENT SETTINGS}

1. I understand personal self-improvement as... (0-4 points)

2. I understand professional self-improvement as... (0-4 points)

3. The interconnection between personal and professional self-improvement, in my opinion, lies in... (04 points)

4. I assess my level of professional competences on a scale from 1-10 in.... points because... (0-4 points)

5. I assess the level of professional competences of my groupmates on a scale of 1-10 in.... points because... (0-4 points)

6. I evaluate my level of psychological readiness for teaching in primary school on a scale from $0-10 \mathrm{in} . .$. points because... (0-4 points)

7. The level of psychological readiness for teaching in primary school of my groupmates on a scale of 010 I evaluate in ... points because... (0-4 points)

8. At this stage, I believe that the following areas of professional self-improvement are relevant to me:... (0-4 points)

9. For professional self-improvement at this stage I take the following measures:... (0-4 points)

10. Do you consider it possible and necessary to spend your own financial resources for professional selfimprovement? Motivate your answer. (0-4 points)

11. What are the publicly available (that do not require significant financial costs) ways of professional self-improvement? Do you know and plan to use them in professional activities? Justify your answer. (0-4 points)

12. What paid ways of professional self-improvement do you know? Which of them do you plan to use in pedagogical activities? (0-4 points)

13. You see favorable preconditions for professional self-improvement within the framework of the active professional activity of the primary school teacher in ... (0-4 points)

14. Factors such as:... may be unfavorable for professional self-improvement. (0-4 points)

15. In the context of university training, I would rate my own professional self-improvement on a scale of $0-10$ points in.... points because... (0-4 points)

16. What / who most stimulates you to self-improvement professionally in the context of university training? Justify your answer. (0-4 points)

17. What factor influenced you the most during professional self-determination? ( $0-4$ points)

18. What do you consider the most attractive factors in the profession of primary school teacher at this stage? (0-4 points)

19. What do you consider the most repulsive factors in the profession of primary school teacher at this stage? (0-4 points)

20. What can make you refuse from the profession of primary school teacher? (0-4 points)

21. What difficulties of professional development can you foresee in the initial stages of your professional activity? (0-4 points)

22. Describe your desired professional image in 5 years. (0-4 points)

23. Describe your undesired professional image in 5 years. (0-4 points)

24. Who / what is a reference point for you in professional self-improvement? (0-4 points)

25. How would you assess the ratio of factors of your professional development? University training: Own efforts for professional growth. (0-4 points) 


\section{APPENDIX B: QUESTIONNAIRE FOR TEACHERS OF PRIMARY SCHOOL WITH WORK EXPERIENCE $\geq 5$ YEARS IN ORDER TO DETERMINE THE DEGREE OF IMPLEMENTATION OF PROFESSIONAL SELF-IMPROVEMENT SETTINGS}

1. How do you understand personal self-improvement? What are you doing for this? (0-4 points)

2. How do you understand professional self-improvement? What are you doing for this? With what regularity (0-4 points)

3. The interconnection between personal and professional self-improvement, in my opinion, lies in... (0-4 points)

4. I assess my level of professional competences on a scale from 1-10 in.... points because... (0-4 points)

5. I assess the level of professional competences of my colleagues on a scale of 1-10 in.... points because... (0-4 points)

6. Does the administration of the school where you work encourage your professional selfimprovement? How exactly? (0-4 points)

7. At this stage, I believe that the following areas of professional self-improvement are relevant to me:... (0-4 points)

8. For professional self-improvement in certain areas at this stage of professional activity, I take the following measures:... (0-4 points)

9. Do you spend your own financial resources for professional self-improvement? How much does it cost on average per year? How often do you have to spend your own money? (0-4 points)

10. What publicly available (that do not require financial costs) ways of professional self-improvement do you know and systematically use in professional activities? Justify your answer. (0-4 points)

11. What paid sources of professional self-improvement for a primary school teacher do you know? Which of them do you actively use in teaching activities? (0-4 points)

12. What favorable preconditions for professional self-improvement can you single out within the framework of your professional activity as a primary school teacher? Justify your answer. (0-4 points)

13. How does the salary affect your professional self-improvement activity? Would it be a significant factor to stimulate professional self-improvement, taking into account the indicators of professional self-improvement within the salary accrual scheme? (0-4 points)

14. You consider the following factors as unfavorable for your professional self-improvement, namely:... (0-4 points)

15. Do you admit the possibility that in the event of a change in the institution of work you will feel more motivated to improve professionally? Why? (0-4 points)

16. What stimulates you most of all towards improving yourself professionally in the framework of pedagogical activities? Justify your answer. (0-4 points)

17. What advantages of your own university training for professional activities, which appeared with the beginning of teaching, could you mention? (0-4 points)

18. What difficulties of professional activity did you face with in the first year after graduation, which you associate with the lack of university training? How far have they been overcome and in what ways? (0-4 points)

19. Have you formed an attitude to self-improvement while studying at the university? Evaluate the result on a scale of 1-10 points and justify your answer. (0-4 points)

20. What do you consider the most repulsive factors in the profession of primary school teacher at this stage? (0-4 points)

21. What can make you refuse from the profession of primary school teacher? (0-4 points)

22. What difficulties of professional development have you still not been able to overcome during the first 5 years of your professional activity? (0-4 points)

23. Describe your desired professional image in 5 years. (0-4 points)

24. Describe your undesired professional image in 5 years. ( $0-4$ points)

25. Who / what is a reference point for you in professional self-improvement? (0-4 points) 